\title{
Elastin: a possible genetic biomarker for more severe ligament injuries in elite soccer. A pilot study
}

\author{
Rosa Artells ${ }^{1 \S}$ \\ Ricard Pruna $2 \$$ \\ Alexandre Dellal ${ }^{3}$ \\ Nicola Maffulli4,
}

$\S$ equally contributed

1 SM Genomics, Barcelona Science Park, Barcelona, Spain

2 FC Barcelona Medical Services, FIFA Medical

Center of Excellence, Barcelona, Spain

${ }^{3}$ FIFA Medical Center of Excellence, Centre

Orhopedique Santy, Lyon, France

4 Department of Musculoskeletal Disorders Faculty of Medicine, Surgery and Dentistry, University of Salerno, Salerno, Italy;

Centre for Sports and Exercise Medicine

Barts and London School of Medicine and Dentistry, Queen Mary University of London, London, UK

\section{Corresponding author:}

Nicola Maffulli

Department of Musculoskeletal Disorders

Faculty of Medicine, Surgery and Dentistry

University of Salerno, Salerno, Italy

E-mail: n.maffulli@qmul.ac.uk

\section{Summary}

Background: The study of new genetic biomarkers in genes related to connective tissue repair and regeneration may help to identify individuals with greater predisposition to injury, who may benefit from targeted preventive measures, and those who require longer recovery time following a muscle, ligament or tendon injury. The present study investigated whether single nucleotide polymorphisms of the Elastin gene could be related to MCL injury.

Methods: 60 top class football players were studied to identify single nucleotide polymorphisms for the Elastin (ELN) gene using Allelic Discrimination analysis. Each player was followed for 7 seasons, and each MCL injury was noted.

Results: Ligament injury rate, severity and recovery time are related to specific genotypes observed in the elastin gene, especially the ELN-AA
(16 MCL) and the ELN-AG (3 MCL). Players with the ELN-GG genotype sustained no MCL injury during the 7 seasons of the study.

Conclusions: The identification of polymorphisms in the ELN gene may be used as a novel tool to better define an athlete's genotype, and help to plan training and rehabilitation programmes to prevent or minimize MCL ligament injuries, and optimize the therapeutic and rehabilitation process after soft tissue injuries, and manage the workloads during trainings and matches.

KEY WORDS: elastin, genetic biomarker, injury prevention, medial collateral ligament injury, SNP, workload.

\section{Introduction}

Injury prevention in elite sport allows to minimize the severity, number of injuries and lay-off during the playing season. In this context, numerous studies have attempted to improve injury prevention strategies with different complementary methods: functional strength with eccentric and isokinetic exercise ${ }^{1,2}$, balance and proprioception training ${ }^{3,4}$, core stability ${ }^{4}$, and mobility. Furthermore, a multicomponent injury prevention-training programme may be appropriate to reduce the number of muscle injuries during a competitive season, but may not be adequate to reduce all other injuries in soccer ${ }^{5}$. The incidence of injuries among elite adult male soccer players during competitive match-play is between 24.6 and 34.8 per 1000 match hours $1,6,7$, and training injuries range between 5.8 to 7.6 per 1000 training hours ${ }^{1,7}$ even though some studies report values outside these ranges ${ }^{8}$.

The knee is the most solicited joint in soccer. Knee injuries involved $18 \%$ of total injuries in Swedish elite soccer players and $16-17 \%$ in elite soccer players from the English Premier League ${ }^{9}$.

Ligament injuries in football usually affect the ankle $(72 \%)$ and knee $(28 \%)$ joints, with the lateral ankle ligamentous complex and the medial collateral ligament respectively being the most frequent. The UEFA studies consider this injury to be the one that involves major time loss, although ACL injuries are more severe but less frequent.

Ligaments are connective tissue structures composed mainly of COL1. Their function is to passively stabilise a joint.

There are two types of ligaments, depending on the amount and distribution of the connective tissue. 
Band-like ligaments help to strengthen the joint capsule, and are attached to other structures in the joint. They are composed of overlapped crisscrossed collagen fibers, which allow multidirectional stability. These ligaments are well vascularized, and show a high metabolic level which will positively affect their repair capabilities. Cord ligaments are composed of parallel and compact fibers, and can with stand tensions in only one direction.

Ligaments are highly innervated and contain a large amount of receptors as well as nociceptors and proprioceptors, which may contribute to enhance their reparative process. Direct or indirect stresses can cause ligament tears ${ }^{10}$.

Injuries have a multifactorial origin as a consequence of both extrinsic and intrinsic factors ${ }^{11}$. Recent studies have begun to focus on the importance of the genetic component, considered as an intrinsic factor, in the pathogenesis of non-contact musculoskeletal soft tissue injuries (NCMSTIs) ${ }^{12-14}$. All these studies show that there is a marked genetic influence in the nature of an injury ${ }^{15}$, higher than $50 \% 13,16$.

The genetics characteristic of players may also provide information regarding this predisposition of $\mathrm{MCL}$ to tear ${ }^{17-19}$.

Ligaments are composed of approximately two thirds of water ${ }^{20}$. The components of the remaining one third include collagen, proteoglycans, elastin (ELN) and other proteins and glycoproteins such as actin, laminin and integrins ${ }^{21}$. The central portion of a ligament is composed of an extensible composite of ELN and collagen fibers ${ }^{22}$. In the terminal region of ligaments, the orientation of the collagen fibrils is longitudinal, and the elastic fibres end within the ligament without any attachment to bone ${ }^{23}$. The presence of single nucleotide polymorphisms (SNPs) in some of these components has been associated with ligament injuries ${ }^{17-19}$. A SNP can occur both in the coding and non-coding regions of a gene, and can affect the response of an individual to a specific treatment or other stimuli24.

We focused our attention on the ELN gene. ELN is a self-assembling extracellular matrix protein, is the major source of tissue elasticity, and is a major component of ligaments and arterial walls. Elastic fibres regulate the activity of matrix tissue, providing elastic recoil and resilience to a variety of connective tissues, including arteries and ligaments. Following an injury, during repair and regeneration the contractile function is lost and cells express an immature ELN phenotype able to proliferate and remain in the extracellular matrix. The absence of elastin distorts the stability of other components of the extracellular matrix. To avoid this, the expression of ELN wild type genotype is necessary ${ }^{25}$. Although COL $1 \mathrm{~A} 1$ and COL5A1 polymorphisms influence the risk of ACL and MCL injuries, to our knowledge no study has attempted to as certain the relationship between MCL injuries and ELN genotype.

This pilot study analyzed the possible relationship between SNPs in the ELN gene and MCL injuries oc- curred in two elite professional football players, who are brothers, compared with other elite professional football players from the same team.

\section{Materials and methods}

\section{Study Design}

This is an observational study where data were collected from 2007 to 2014. In this report, we focused on the medial collateral ligament (MCL) injuries that occurred between 2007 and 2014, and their relation to the ELN genotype. All the players gave their consent after a detailed explanation about the study procedure and risks involved with the investigation.

All procedures were performed according to what described in Padulo et al. ${ }^{26}$

\section{Subjects}

Sixty top elite professional European soccer players took part in this study (age: $25.52 \pm 2.5 y e a r s ~(19-35)$; height: $179.62 \pm 2.5 \mathrm{~cm}(166-195)$; body-mass index (BMI): $76.44 \pm 2.5 \mathrm{~kg}$ (64-92), Body Fat (BF\%): $8.66 \pm 2.5 \%(6.9-12.9)$. All the players played in the UEFA Champion's League, French League-1, Spanish League and English Premier League, trained between 6 and 10 hours per week, and played 1 or 2 competitive matches per week throughout the season.

\section{Genetics samples}

We obtained DNA from blood samples using QIAmp DNA Blood Minikit (Qiagen, Valencia, CA) following the manufacturer's instructions. We performed Allelic Discrimination analysis using an ECO Real Time PCR System (Illumina, CA) following the standard protocol in SM Genomics, SL laboratory located in Barcelona Science Park (Barcelona, Catalonia, Spain). Primers and probes for ELN (rs2289360) were obtained from Applied Biosystems (AB, SNP Genotyping Assay, Foster City, CA). The presence of two probes allows the detection of both alleles in a single test tube. Moreover, because probes are included in the PCR, genotypes are determined without any post-PCR processing, a feature unavailable to most other genotyping methods ${ }^{27}$. TaqMan PCR assay has been successfully used to discriminate alleles that differ by a single base substitution. This procedure provides a quick and reliable alternative to other electrophoresis-based techniques ${ }^{28,29}$.

\section{Statistical analysis}

In a previous study ${ }^{19}$ we genetically analyzed a population of professional football players and studied the association between their genetic profile and severity and recovery time of non-contact soft tissue muscu- 
R. Artells et al.

loskeletal injuries. The association between type and degree of injury and the SNPs analyzed was ascertained with the Chi-Square test and Fisher's exact Test when necessary. The association between SNPs and injury recovery time was evaluated using multivariate analysis of variance. All statistical analyses were performed using SPSS version 14.0 for Windows (SPSS Inc., Chicago, IL). Significance was set at $\mathrm{P}<=0.05$. The Benjamini-Hochberg $\mathrm{P}$-value corrective test for multiple comparisons was applied ${ }^{19}$.

\section{Results}

A total of 60 professional football players were genotyped. 17 players presented the AA genotype (28.33\%), 35 the AG (58.33\%), and 8 presented the GG genotype (13.33\%). During seven consecutive seasons, a total of $19 \mathrm{MCL}$ injuries were recorded. All injuries were diagnosed by clinical examination, and confirmed by US and MRI. MCL injuries were classified as grade 2 and 3 (Tab. I).

The Medical Staff of FC Barcelona reported problems with two players, who are brothers, who suffered an increased number of $\mathrm{MCL}$ injuries compared to the other players during the seasons studied. Specifically, these two players experienced 8 of the 19 injuries recorded $(42.10 \%)$. Table II summarizes the player's information. Both players exhibited an AA genotype for the ELN gene. In addition to the large number of injuries that these two individuals suffered, their recovery time was inordinately long.

\section{Discussion}

Epidemiologic studies are useful to give information on the prevalence of soft tissue injuries, and to try and detect risk factors and develop preventives strategies $^{30}$. Recently, genetics shed some light in the identification of new biomarkers that could help medical staff and coaches to objectify risks factors ${ }^{19}$. SNPs in the genes that codify for the proteins in the musculoskeletal soft tissues could induce weakness in such structures. SNPs in the genes that codify for the proteins in the musculoskeletal soft tissues could induce weakness in such structures ${ }^{31-33}$.

The main finding of the present study is that ELN might be used as a biomarker of weaknesses in ligaments, and provide information on the risk to suffer from a severe injury. ELN, a self-assembling extracellular matrix protein, is the major source of tissue elasticity ${ }^{34}$. Some SNPs are located in an intronic region, susceptible to be targeted by miRNAs, such as miR$N A-29^{35}$. miRNAs can affect the final protein by $\mathrm{mR}$ NA inhibition or mRNA degradation, leading to an altered function or expression of the final protein ${ }^{36}$.

Individuals with the AA genotype in ELN experience severe ligament injuries (grade 3 ) $(>50 \%$ of connective tissue damage) and long recovery times (>80 days). Hanon et al. ${ }^{37}$ found a relationship between SNPs in ELN with age and arterial compliance in 320 individuals with no symptoms of cardiovascular disease. They found that carriers of the A allele exhibited decreased arterial compliance compared to carriers of the homozygous GG variant. Pruna et al. ${ }^{19}$

Table I. Number of observed ligament injuries medial (collateral ligament $=\mathrm{MCL}$ ) according to elastin $(\mathrm{ELN})$ genotype of soccer players.

\begin{tabular}{cccc}
\hline Gene & $\mathbf{N}^{\circ}$ Players & ELN Genotype & $\begin{array}{c}\mathbf{N}^{\circ} \text { Ligament Injuries } \\
\text { MCL }\end{array}$ \\
\hline ELN & 17 & AA $(28.33 \%)$ & 16 \\
& 35 & AG $(58.33 \%)$ & 3 \\
& 8 & GG $(13.33 \%)$ & 0 \\
\hline
\end{tabular}

Table II. Medial collateral ligament (MCL) injury descriptors in the two players studies.

\begin{tabular}{lccccc}
\hline Player & $\begin{array}{c}\text { Total number } \\
\text { of MCL injuries }\end{array}$ & Grade & Days of absence & Total days of absence & Genotype \\
\hline 1 & 2 & 65 & 250 & AA \\
& 2 & 56 & & \\
& 2 & 51 & & \\
\hline 2 & 2 & 76 & 545 & \\
& 2 & 124 & & \\
& 2 & 66 & & \\
& 2 & 83 & & \\
& 2 & 272 & & \\
\end{tabular}


have showed that ELN-AA was associated with greater severity of ligament injury and longer recovery time than ELN-AG and ELN-GG. Both players described in this report presented the ELN-AA genotype, which is associated with greater $\mathrm{MCL}$ injury rate, severity and longer recovery time.

Eight of the $16 \mathrm{MCL}$ injuries in players with genotype AA (50\%) occurred in these two players, who also experienced longer recovery time than expected. The presence of the homozygous AA SNP in ELN might help to identify elite soccer players with a high predisposition to suffer from severe ligament injuries. This genetic information was in line with the observations of the Medical Staff regarding the injuries suffered by these two players during the 7 seasons under study, and could be useful to plan a more progressive rehabilitation and introduction of loads during training to recover fully and avoid reinjuries.

Our data are consistent with our hypothesis, but our study does have limitations: 1) the study of genetic profiles in sports medicine is still in its early stages, and cause-effect data have not been obtained yet; 2) there is low accessibility to elite professional athletes; 3 ) the investigation is an observational study based only two elite players, who were brothers, after MCL injuries.

\section{Conclusion}

Many studies have offered epidemiological explanations for sports injuries but genetic profiles could be used to better define the risk of injury of a given individual, allowing more specific treatment and prevention.

The study of SNPs, despite being in its infancy, constitutes a novel field of investigation in sports medicine and traumatology, and might help to identify individuals with a shorter recovery time and greater response to treatment and those at a greater risk of injury ${ }^{17,30}$.

These preliminary results indicate that SNPs in the ELN gene could help to plan more effective prevention protocols, and in the management of training loads to adapt and convert weakness into strengths. In addition, these biomarkers could become useful adjuncts to return to play criteria.

Further studies with larger samples are warranted to validate our findings.

\section{Abbreviations}

ELN: elastin; SNP: single nucleotide polymorphism; NCMSTI: non-contact musculoskeletal soft tissue injuries; ACL: anterior cruciate ligament; MCL: medial collateral ligament.

\section{Ethical approval}

The study was approved by the Ethics Committee of the Hospital Clinic, Barcelona (registry no. 2012/7117).

\section{Conflicts of interests}

The Authors declare that they have no competing interests.

\section{Authors' Contributions}

RP and RA designed the study, interpreted the results, wrote the manuscript and accepted the final version of it. $A D$ and NM wrote the first draft of the manuscript and accepted the final version of it. All the Authors read and accepted the final version of the manuscript.

\section{Acknowledgements}

We would like to thank FC Barcelona Medical Services and for all data provided.

\section{References}

1. Arnason A, Andersen T, Holme I, Engebretsen L, Bahr R. Prevention of hamstring strains in elite soccer: an intervention study. Scand J Med Sci Sports. 2008;18(1):40-48.

2. Askling C, Karlsson J, Thorstensson A. Hamstring injury occurrence in elite soccer players after preseason strength training with eccentric overload. Scand J Med Sci Sports. 2003;13 (4):244-250.

3. Engebretsen AH, Myklebust G, Holme I, Engebretsen L, Bahr R. Prevention of Injuries Among Male Soccer Players A Prospective, Randomized Intervention Study Targeting Players With Previous Injuries or Reduced Function. Am J Sports Med. 2008;36(6):1052-1060.

4. Willardson JM. Core stability training: applications to sports conditioning programs. J Strength Cond Res. 2007;21(3):979985.

5. Owen AL, Wong DP, Dellal A, Paul DJ, Orhant E, Collie S. Effect of an injury prevention program on muscle injuries in elite professional soccer. J Strength Cond Res. 2013;27(12):32753285.

6. Parry L, Drust B. Is injury the major cause of elite soccer players being unavailable to train and play during the competitive season? Phys Ther Sport. 2006;7(2):58-64.

7. Waldén $M$, Hägglund $M$, Ekstrand J. UEFA Champions League study: a prospective study of injuries in professional football during the 2001-2002 season. Br J Sports Med. 2005;39(8):542-546.

8. Dellal A, Chamari K, Owen A. How and When to Use an Injury Prevention Intervention in Soccer, Muscle Injuries in Sport Medicine, Prof. Gian Nicola Bisciotti (Ed.) 2013.

9. Hägglund $M$, Waldén $M$, Ekstrand J. Previous injury as a risk factor for injury in elite football: a prospective study over two consecutive seasons. Br J Sports Med. 2006;40(9):767-772.

10. Hoffmann $A$, Gross $G$. Tendon and ligament engineering in the adult organism: mesenchymal stem cells and gene-therapeutic approaches. Int Ortho. 2007;31:791-797.

11. Fuller CW, Junge A, Dvorak J. Risk management: FIFA's approach for protecting the health of football players. Br J Sports Med. 2012;46(1):11-17.

12. Laguette M-J, Abrahams $Y$, Prince S, Collins M. Sequence variants within the $3^{\prime}$-UTR of the COL5A1 gene alters mRNA stability: implications for musculoskeletal soft tissue injuries. Matrix Biol. 2011;30(5):338-345. 
13. Lippi G, Longo UG, Maffulli N. Genetics and sports. Br Med Bull. 2010;93(1):27-47.

14. Magra M, Maffulli N. Genetic aspects of tendinopathy. J Sci Med Sport. 2008;11(3):243-247.

15. Johnson JS, Morscher MA, Jones KC, Moen SM, Klonk CJ, Jacquet R, et al. Gene Expression Differences Between Ruptured Anterior Cruciate Ligaments in Young Male and Female Subjects. Bone Joint J. 2015;97(1):71-79.

16. Puthucheary Z, Skipworth JR, Rawal J, Loosemore M, Van Someren K, Montgomery HE. Genetic influences in sport and physical performance. Sports Medicine. 2011;41(10):845859.

17. Kambouris M, Ntalouka F, Ziogas G, Maffulli N. Predictive genomics DNA profiling for athletic performance. Recent Pat DNA Gene Seq. 2012;6(3):229-239.

18. Longo UG, Loppini M, Margiotti K, Salvatore G, Berton A, Khan WS, et al. Unravelling the genetic susceptibility to develop ligament and tendon injuries. Curr Stem Cell Res Ther. 2013;10(1):56-63.

19. Pruna R, Artells R, Ribas J, Montoro B, Cos F, Muñoz C, et al. Single nucleotide polymorphisms associated with non-contact soft tissue injuries in elite professional soccer players: influence on degree of injury and recovery time. BMC Musculoskelet Disord. 2013;14(1):221.

20. Hoffmann A, Gross $G$. Tendon and ligament engineering in the adult organism: mesenchymal stem cells and gene-therapeutic approaches. Int Orthop. 2007;31(6):791-797.

21. Frank C. Ligament structure, physiology and function. J Musculoskelet Neuronal Interact. 2004;4(2):199.

22. Brown RE, Butler JP, Rogers RA, Leith DE. Mechanical connections between elastin and collagen. Connect Tissue Res.1994;30(4):295-308.

23. Serafini-Fracassini A, Field J, Smith J, Stephens W. The ultrastructure and mechanics of elastic ligaments. Elastin and Elastic Tissue: Springer. 1977;97-103.

24. Colomer R, Monzo M, Tusquets I, Rifa J, Baena JM, Barnadas $A$, et al. A single-nucleotide polymorphism in the aromatase gene is associated with the efficacy of the aromatase inhibitor letrozole in advanced breast carcinoma. Clinical Can Res. 2008;14(3):811-816.

25. Hanon O, Luong V. Aging, carotid artery distensibility, and the Ser422Gly elastin gene polymorphism in humans. Hypertension. 2001;38:1185-1189.

26. Padulo J, Oliva F, Frizziero A, Maffulli N. Muscles, Ligaments and Tendons Journal. Basic principles and recommendations in clinical and field science research: 2016 update. MLTJ. 2016;6 (1):1-5

27. Hui L, Del Monte T, Ranade K. Genotyping using the TaqMan assay. Curr Protoc Hum Genet. 2008.

28. Livak KJ. Allelic discrimination using fluorogenic probes and the 5' nuclease assay. Genet Anal. 1999;14(5):143-149.

29. Salvi S, Tuberosa R, Phillips RL. Development of PCR-based assays for allelic discrimination in maize by using the $5^{\prime}$-nuclease procedure. Mol Breed. 2001;8(2):169-176.

30. Kambouris M, Del Buono A, Maffulli N. Genomics DNA Profiling in Elite Professional Soccer Players: A Pilot Study. Transl Med Unisa. 2014;9:18.

31. Magra M, Maffulli N. Genetic aspects of tendinopathy. J Sci Med Sport. 2008;11:243-247.

32. Bryan BA, Mitchell C. Modulation of muscle regeneration, myogenesis, and adipogenesis by the Rho family guanine nucleotide exchange factor GEFT. Mol Cell Biol. 2005;25(24): 11089-11101.

33. Devaney JM, Hoffman EP. IGF-II gene region polymorphisms related to exertional muscle damage. J Appl Physiol. 2007; 102:1815-1823.

34. Muiznieks LD, Weiss AS, Keeley FW. Structural disorder and dynamics of elastin. Biochem Cell Biol. 2010;88(2):239-250.

35. Dong XR, Majesky MW. Restoring elastin with microRNA-29. Arterioscler Thromb Vasc Biol. 2012;32(3):548-551.

36. Hayes CN, Chayama K. MicroRNAs as Biomarkers for Liver Disease and Hepatocellular Carcinoma. International Journal of Molecular Sciences. 2016;17(3):280.

37. Hanon O, Luong V, Mourad JJ, Bortolotto LA, Jeunemaitre X, Girerd X. Aging, carotid artery distensibility, and the Ser422Gly elastin gene polymorphism in humans. Hypertension. 2001;38(5):1185-1189. 